УДК 539.219

DOI: $10.21779 / 2542-0321-2021-36-3-51-57$

\title{
Н.В. Офицерова
}

\section{Особенности электропроводности карбидкремниевой керамики}

\author{
Дагестанский государственный университет; Россия, 367000, \\ 2. Махачкала, ул. М. Гаджиева, 43a; kalinof2002@mail.ru
}

В статье приведены результаты исследования влияния вводимого второго компонента $(\geq 30 \%)$ на электропроводность $\mathrm{SiC}$ керамики. Объектами исследования служили образцы керамики на основе $\mathrm{SiC}$ с добавками $\mathrm{AlN}$ и $\mathrm{NbC}$ ( 30 и 70 вес. \%). Керамика, содержащая металлический карбид ниобия, спекалась при двух температурах -1900 и $2200{ }^{\circ} \mathrm{C}$.

Установлено, что введение AlN в карбидкремниевую керамику приводит к резкому снижению проводимости по сравнению с другими образцами. Вероятно, это связано с увеличением количества примесей $\mathrm{Al}$ в узлах $\mathrm{Si}$, действующих как глубокие акцепторные ловушки для носителей, создаваемых азотом. Энергия активации проводимости растёт в соответствии с шириной запрещённой зоны, что свидетельствует в пользу образования твердого раствора в системе $\mathrm{SiC}-\mathrm{AlN}$.

Электропроводность керамики $\mathrm{SiC}-\mathrm{NbC}$ зависит как от содержания карбида ниобия, так и от температуры спекания. Установлено, что в керамике $\mathrm{SiC}-\mathrm{NbC}$, спеченной при $\mathrm{T}=1900^{\circ} \mathrm{C}$, электропроводность растет с увеличением содержания карбида ниобия. Однако при содержании 70 вес. \% $\mathrm{NbC}$ керамика демонстрирует металлическую проводимость. Это подтверждает данные рентгеноструктурного анализа о том, что данная керамика представляет собой механическую смесь $\mathrm{SiC}$ и $\mathrm{NbC}$.

$\mathrm{B}$ свою очередь, электропроводность керамики $\mathrm{SiC}-\mathrm{NbC}$, спеченной при температуре $2200{ }^{\circ} \mathrm{C}$, как и результаты рентгеноструктурного анализа, свидетельствует об образовании полупроводникового твердого раствора в данной системе.

Ключевые слова: керамика, карбид кремния, проводимость, нитрид алюминия, карбид ниобия.

\section{Введение}

По сравнению с металлами керамика обладает более высокими механическими характеристиками, коррозионной стойкостью и устойчивостью к радиационным воздействиям, что обусловливает долговечность керамических конструкций при эксплуатации в агрессивных средах. Карбидкремниевая керамика обладает большим потенциалом для широкого использования в качестве подложек для ИМС, конструкционного материала для изготовления высокотемпературных устройств, форсунок горелок, теплообменников, фильтров для горячих газов и расплавов металлов, установок для сжигания газов.

Свойства карбида кремния делают его отличным материалом для устройств высокой мощности (имеют РЧ выходную мощность порядка 5 Вт/мм) и частоты (от 5,2 до 10,9 ГГц и потенциально до К-диапазона (20-40 ГГц)). Большая ширина запрещенной зоны карбида кремния (2,2-3,26 эВ для различных по- 
литипов) по сравнению с кремнием (1,12 эВ) позволяет устройствам функционировать при повышенных температурах $\left(\sim 1000{ }^{\circ} \mathrm{C}\right)$. Очень высокое пробивное напряжение этих материалов ( $\approx 1,8-3,8 \mathrm{MB} / \mathrm{cm})$, которое примерно в 10 раз выше, чем у $\mathrm{Si}(0,3 \mathrm{MB} / \mathrm{cm})$, позволяет уменьшить толщину областей проводимости (при постоянном уровне легирования), что приводит к очень низкому удельному сопротивлению.

Введение различных добавок в карбидкремниевую керамику изменяет не только ее структуру, но и электропроводность [1-6]. Особенностью такой керамики является то, что даже при больших количествах второго компонента, сохраняются уникальные свойства карбида кремния: высокая химическая, механическая и радиационная стойкость. Собственная проводимость $\mathrm{SiC}$ наблюдается при температурах свыше $1400{ }^{\circ} \mathrm{C}$, поэтому при более низкой температуре проводимость карбидкремниевой керамики определяется вводимыми добавками. В статье приведены результаты исследования влияния вводимого второго компонента ( $\geq 30$ \%) на электропроводность керамики.

\section{Результаты и обсуждение}

Объектами исследования служили образцы керамики на основе $\mathrm{SiC}$ с добавками $\mathrm{AlN}$ и $\mathrm{NbC}$ ( 30 и 70 вес. \%). Керамика, содержащая металлический карбид ниобия, спекалась при двух температурах - 1900 и $2200{ }^{\circ} \mathrm{C}$, что позволило оценить и влияние технологических условий на электропроводность образцов. Добавки были выбраны, т. к., согласно оценкам авторов [7], именно Al, $\mathrm{N}$ и $\mathrm{Nb}$ обладают максимальной растворимостью в карбиде кремния.

Образцы керамики размером $2 \times 5 \times 12$ мм $^{3}$ были получены горячим прессованием по технологии, описанной в [7]. Измерения температурной зависимости электропроводности керамики проводились четырехзондовым методом в диапазоне температур 300-1800 ${ }^{\circ} \mathrm{C}$. Погрешность измерений температуры составляла от 0,5 до 10 К в исследуемом интервале температур.

Результаты измерений температурной зависимости электропроводности представлены на рис. 1 (для $30 \%$ содержания второго компонента) и на рис. 2 (для 70 \%). Для сравнения на рисунках приведены температурные зависимости электропроводности для керамики из чистого $\mathrm{SiC}$.

Как видно, в своем большинстве зависимость $\ln \sigma=f\left(10^{4} / \mathrm{T}\right)$ для исследованных образцов керамики имеет характер типичный для полупроводников или диэлектриков. Заметим, что проводимость керамики с добавками $\mathrm{NbC}$ зависит и от температуры спекания.

$\mathrm{C}$ одной стороны, $\mathrm{SiC}$ и $\mathrm{AlN}$ - материалы для высокотемпературной конструкционной керамики. C другой - $\mathrm{AlN}$ и политип $2 \mathrm{H}-\mathrm{SiC}$ являются изоструктурными, что делает возможным [7] образование в этой системе непрерывных твердых растворов замещения при температурах $2000{ }^{\circ} \mathrm{C}$.

Как видно из рис. 1 и 2, введение в $\mathrm{SiC}$ керамику нитрида алюминия в любых количествах приводит к снижению проводимости и тенденции к росту удельного сопротивления с увеличением содержания AIN. Заметная проводимость в керамике $\mathrm{SiC}-\mathrm{AlN}$ (при содержании $\mathrm{AlN} \geq 30$ вес. \%) наблюдается только при температурах свыше 1100 К. Это понятно, так как, с одной стороны, AlN является широкозонным полупроводником (почти диэлектриком с $\mathrm{E}_{\mathrm{g}}=6,2$ эВ). С другой - 
вероятно, увеличение количества $\mathrm{Al}$ в узлах $\mathrm{Si}$ приводит к образованию глубоких акцепторных ловушек для носителей, создаваемых азотом [8].

Оценка энергии активации проводимости показывает, что в данной керамике с ростом содержания AIN она растёт в соответствии с шириной запрещённой зоны. Однако рост содержания AIN (до 70 вес. \%) приводит к увеличению удельного электрического сопротивления из-за: 1) увеличения атомов Al, действующих как глубокие акцепторы для захвата носителей, создаваемых азотом; 2) образования твердого раствора в системе $\mathrm{SiC}-\mathrm{AlN} ; 3)$ наличия электроизоляционных слоев AlN на границах зерен [9].

Изменение проводимости и соответственно величины удельного сопротивления для керамики с различным содержанием нитрида алюминия объясняется особенностями зонной структуры твердого раствора, образующегося в системе $\mathrm{SiC}-\mathrm{AlN}[10]$. Расстояние между валентной зоной и зоной проводимости с ростом содержания AlN увеличивается, и при составах 70 вес. \% AlN происходит переход от «непрямой» к «прямой» структуре энергетических зон [10].

В целом проводимость керамики в системе $\mathrm{SiC}-\mathrm{AlN}$ с ростом температуры растет, что является типичным для полупроводников. Однако для образца с 70 вес. \% AlN наблюдается аномальное увеличение сопротивления приблизительно на порядок, что согласуется с данными авторов [11].

Вероятно, с ростом температуры изменяется подвижность носителей заряда, связанная с рассеянием на ионизированных примесях, чем и обусловлен полученный результат. При перестройке зонной структуры также происходит изменение типа химической связи (на донорно-акцепторную характерную для соединений типа $\mathrm{A}^{3} \mathrm{~B}^{5}$ ), чем, вероятно, и обусловлено высокое сопротивление образца с 70 вес. $\%$ AlN.

Аналогичные исследования для карбидкремниевой керамики с $\mathrm{NbC}$, спеченной при температурах 1900 и $2200{ }^{\circ} \mathrm{C}$, показали (рис. 1), что для керамики $\mathrm{SiC}-\mathrm{NbC}$, спеченной при $1900{ }^{\circ} \mathrm{C}$, при 30 вес. \% содержании карбида ниобия проводимость незначительно растет по сравнению с керамикой из чистого карбида кремния. Ход зависимости проводимости, все еще характерный для полупроводников, обусловлен влиянием карбида кремния.

При высоком содержании $\mathrm{NbC}$ ( 70 вес. \%) температурная зависимость электропроводности приобретает вид, характерный для металлов (рис. 2). Наблюдается резкое увеличение абсолютных значений проводимости, а с ростом температуры проводимость падает. Такое поведение проводимости легко объяснимо, т. к. по данным рентгено-дифракционного анализа [12] эта керамика представляет собой механическую смесь $\mathrm{SiC}$ и $\mathrm{NbC}$. Поскольку в данной керамике преобладает металлический карбид ниобия, то увеличивается доля зерен с металлической связью, которая обуславливает металлический характер проводимости. Минимальная величина удельного сопротивления достигается при 70 вес. \% NbC, когда проводимость целиком определяется карбидом ниобия.

Интересный результат получен для образцов керамики, спеченных при температуре $2200{ }^{\circ} \mathrm{C}$ (рис. 1 и 2). Наблюдаемые зависимости проводимости и данные рентгеноструктурного анализа [12] свидетельствуют в пользу образования твердого раствора в системе $\mathrm{SiC}-\mathrm{NbC}$. Уже при $30 \% \mathrm{NbC}$ растет проводимость керамики, меняется энергия активации (наклон зависимости). Наблюдаемые при высоких температурах пик (рис. 1) и некоторое снижение проводимости, по- 
видимому, связаны с температурными изменениями подвижности носителей, поставляемых карбидом ниобия.

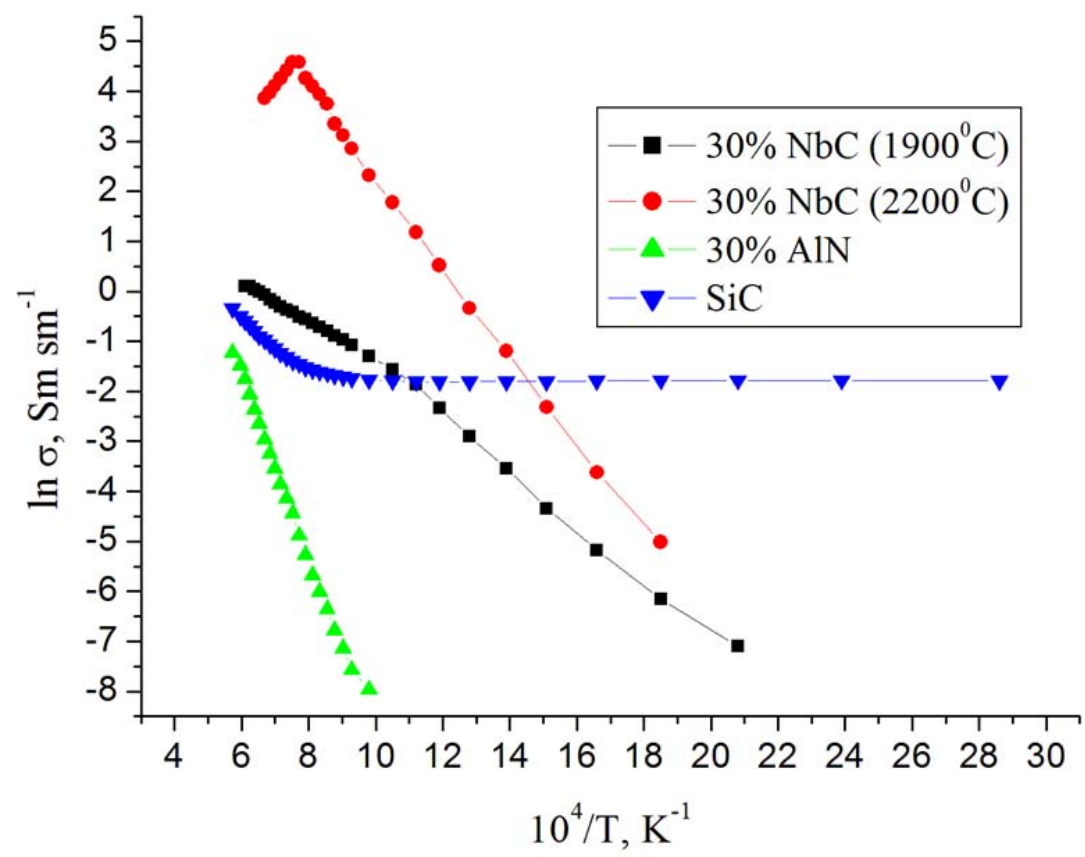

Рис. 1. Температурные зависимости керамики на основе $\mathrm{SiC}$ при $30 \%$-ном содержании второго компонента

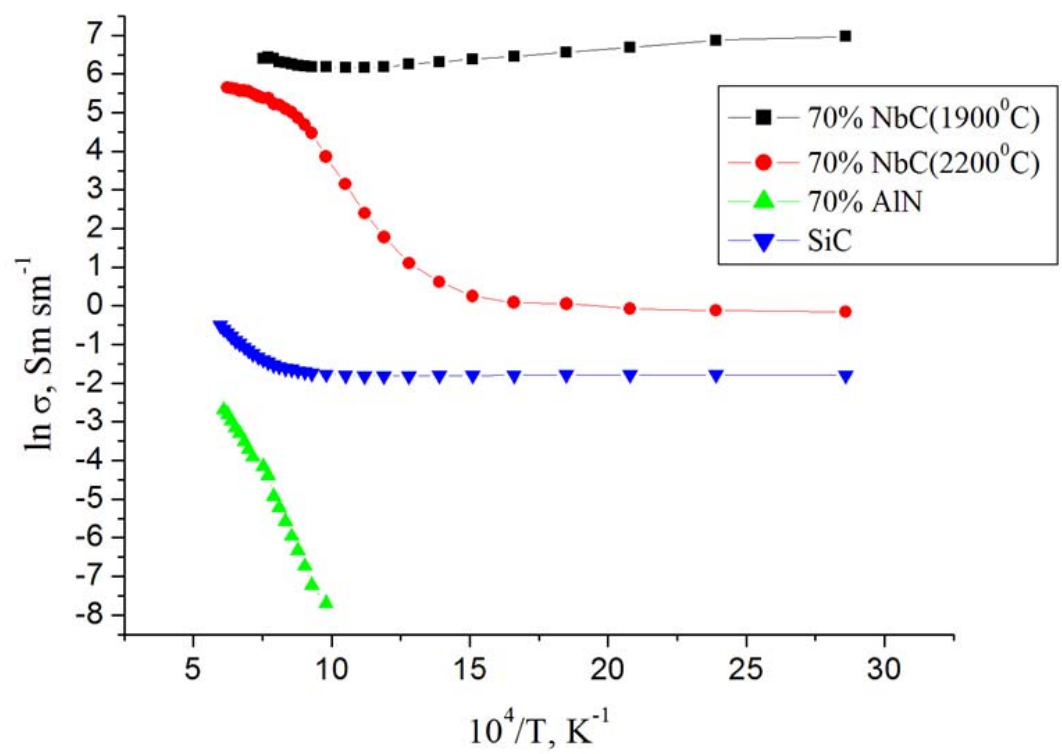

Рис. 2. Температурные зависимости керамики на основе $\mathrm{SiC}$ при 70\%-ном содержании второго компонента

При 70\%-ном содержании $\mathrm{NbC}$ в керамике, спеченной при $2200{ }^{\circ} \mathrm{C}$, вид зависимости меняется (рис. 2). Ее характер свидетельствует о том, что мы имеем дело с сильнолегированным полупроводником или даже полуметаллом. В низко- 
температурной области проводимость керамики почти не меняется (энергия активации порядка 0,103 эВ). По-видимому, это связано с тем, что вся имеющаяся в твердом растворе примесь ионизирована. Кроме того, количество $\mathrm{NbC}$ позволяет предположить, что в твердом растворе возникает примесная зона, перекрывающаяся с зоной проводимости, что приводит к уменьшению запрещенной зоны. При низких температурах проводимость в твердом растворе $\mathrm{SiC}-\mathrm{NbC}$ идет по примесной зоне, а рост проводимости при высоких температурах связан с собственной проводимостью в $\mathrm{SiC}$ (приведенная ширина запрещенной зоны порядка 2,5 эВ).

В отличие от керамики, полученной при $1900{ }^{\circ} \mathrm{C}$, кривая температурной зависимости электропроводности керамики, спеченной при $2200{ }^{\circ} \mathrm{C}$, свидетельствует об образовании поликристаллического полупроводникового твердого раствора. При содержании $\mathrm{NbC}$ свыше 50 вес. \% энергия активации в области низких температур падает до 0,103 эВ, что, вероятно, связано с изменением типа химической связи от ковалентной $(\mathrm{SiC})$ к металлической $(\mathrm{NbC})$. В области высоких температур энергия активации меняется незначительно по сравнению с 30\%-ным содержанием $\mathrm{NbC}$ (рис. 1) и, вероятно, обусловлена собственной проводимостью $\mathrm{SiC}$.

\section{Выводы}

Установлено, что введение AIN в карбидкремниевую керамику приводит к резкому снижению проводимости по сравнению с другими образцами. Вероятно, это связано с увеличением количества примесей $\mathrm{Al}$ в узлах $\mathrm{Si}$, действующих как глубокие акцепторные ловушки для носителей, создаваемых азотом. Энергия активации проводимости растёт в соответствии с шириной запрещённой зоны, что свидетельствует в пользу образования твердого раствора в системе $\mathrm{SiC}-\mathrm{AlN}$.

Электропроводность керамики $\mathrm{SiC}-\mathrm{NbC}$ зависит как от содержания карбида ниобия, так и от температуры спекания. Установлено, что в керамике $\mathrm{SiC}-\mathrm{NbC}$, спеченной при $\mathrm{T}=1900{ }^{\circ} \mathrm{C}$, электропроводность растет с увеличением содержания карбида ниобия. Однако при содержании 70 вес. \% NbC керамика демонстрирует металлическую проводимость. Это подтверждает данные рентгеноструктурного анализа [12] о том, что данная керамика представляет собой механическую смесь $\mathrm{SiC}$ и $\mathrm{NbC}$.

$\mathrm{B}$ свою очередь, электропроводность керамики $\mathrm{SiC}-\mathrm{NbC}$, спеченной при температуре $2200{ }^{\circ} \mathrm{C}$, как и результаты рентгеноструктурного анализа [12], свидетельствует об образовании полупроводникового твердого раствора в данной системе.

\section{Литература}

1. Kwang Joo Kim, Kwang-Young Lim, Young-Wook Kim. Electrical and Thermal Properties of SiC Ceramics Sintered With Yttria and Nitrides // Journal of the American Ceramic Society - June 2014. - № 97 (9). - Pp. 715-718.

2. Kwang Joo Kim, Young-Wook Kim, Kwang-Young Lim et al. Electrical and Thermal Properties of SiC-AlN Ceramics Without Sintering Additives // Journal of the European Ceramic Society. - September 2015. - № 35 (10). - Pp. 2715-2721.

3. Jiaqi Zheng, Jian Chen, Xue-Jian Liu et al. New insights into linear electrical properties of pressureless sintered $\mathrm{SiC}-\mathrm{MoSi}_{2}-\mathrm{AlN}$ composites // Journal of the European Ceramic Society. - November 2018. - № 39 (4). - Pp. 1-7. 
4. Li P.W., Wang C.B., Liu H.X. et al. Structural, thermal and dielectric properties of AlN-SiC composites fabricated by plasma activated sintering // Advances in Applied Ceramics. - February 2019. - № 118 (6). - Pp. 1-8.

5. Young-Wook Kim, Yh. Kim, Kwang Joo Kim. Electrical properties of liquidphase sintered silicon carbide ceramics: a review // Critical Reviews in Solid State and Material Sciences. - January 2020. - № 45 (1). - Pp. 66-84.

6. Офицерова Н.В., Сафаралиев Г.К., Савина В.И., Гаджиев А.А. Электрические свойства керамики на основе карбида кремния с различными добавками // Вестник ДГУ. Сер.: Естественные науки. - 2008. - Вып. 6. - С. 28-33.

7. Сафаралиев Г.К. Твердые растворы на основе карбида кремния. - М.: Физматлит, 2011. - 296 с.

8. Kwang Joo Kim, Young-Wook Kim, Kwang-young Lim et al. Electrical and Thermal Properties of SiC-AlN Ceramics Without Sintering Additives // Journal of the European Ceramic Society. - 2015. - № 35 (10). - Pp. 2715-2721.

9. Rohit Malik, Young-Wook Kim. Effect of AlN addition on the electrical resistivity of pressureless sintered $\mathrm{SiC}$ ceramics with $\mathrm{B}_{4} \mathrm{C}$ and $\mathrm{C} / /$ Journal of the American Ceramic Society. - July 2021.

10. Нурмагомедов Ш.А., Пихтин А.Н., Разбегаев В.Н. и др. Получение и исследование эпитаксиальных слоёв широкозонных твёрдых растворов ( $\mathrm{SiC})_{1-}$ х $(\mathrm{AlN})_{\text {х }} / /$ Письма в ЖТФ. - 1986. - Т. 12, вып. 17. - С. 1043-1045.

11. Ryota Kobayashi, Junichi Tatami, Toru Wakihara et al. Electrical Properties of AlN-SiC Ceramics // Key Engineering Materials. - 2006. - Vol. 317-318. Pp. 641-644.

12. Сараралиев Г.К., Шабанов Ш.Ш., Билалов Б.А., Садыков С.А. Структура и электропроводность керамики $\mathrm{SiC}-\mathrm{NbC} / /$ Вестник Дагестанского государственного университета. - 2011. - Вып. 6. - С. 31-34.

UDC 539.219

Поступила в редакциию 1 июня 2021 г.

DOI: $10.21779 / 2542-0321-2021-36-3-51-57$

\section{The Electrical Conductivity Features of the Silicon Carbide Ceramics}

\section{N.V. Oficerova}

Dagestan State University; Russia, 367000, Makhachkala, M. Gadzhiev st., 43a; kalinof2002@mail.ru

The effect of the introduced second component ( $\geq 30 \%$ ) on the electrical conductivity of $\mathrm{SiC}$ ceramics is investigated. The objects of the study were samples of ceramics based on $\mathrm{SiC}$ with additives AlN and $\mathrm{NbC}$ ( $\sim 30$ and $70 \%$ by weight). Ceramics containing the niobium carbide were sintered at two temperatures of 1900 and $2200^{\circ} \mathrm{C}$.

The research has found that the introduction of AlN into silicon carbide ceramics leads to a sharp decrease in conductivity compared to other samples. This is probably due to an increase in the amount of Al impurities in the Si nodes, acting as deep acceptor traps for carriers created by nitrogen. The activation energy of the conductivity increases in accordance with the 
band gap width, which indicates in favor of the formation of a solid solution in the $\mathrm{SiC}-\mathrm{AlN}$ system.

The electrical conductivity of $\mathrm{SiC}-\mathrm{NbC}$ ceramics depends on both the niobium carbide content and the sintering temperature. It is established that in $\mathrm{SiC}-\mathrm{NbC}$ ceramics sintered at $\mathrm{T}=1900{ }^{\circ} \mathrm{C}$, the electrical conductivity increases with an increase in the content of niobium carbide. However, with a content of $70 \%$ weight. NbC ceramics demonstrate metallic conductivity. This confirms the data of X-ray diffraction analysis that this ceramic is a mechanical mixture of $\mathrm{SiC}$ and $\mathrm{NbC}$.

In turn, the electrical conductivity of $\mathrm{SiC}-\mathrm{NbC}$ ceramics sintered at a temperature of $2200{ }^{\circ} \mathrm{C}$, as well as the results of $\mathrm{X}$-ray diffraction analysis, indicates the formation of a semiconductor solid solution in this system.

Keywords: ceramics, silicon carbide, conductivity, aluminum nitride, niobium carbide.

Received 1 June 2021 